\title{
Evaluation of the Diagnostic and Prognostic Value of CSF Presepsin Levels in Patients with Postneurosurgical Ventriculitis/Meningitis
}

\author{
Guanghui Zheng ${ }^{1-3, *}$ \\ Chenxi Zhang ${ }^{1-3, *}$ \\ Guojun Zhang ${ }^{\text {-3 }}$ \\ Chunqing Shao ${ }^{1-3}$ \\ 'Department of Clinical Diagnosis, \\ Laboratory of Beijing Tiantan Hospital \\ and Capital Medical University, Beijing, \\ People's Republic of China; ${ }^{2}$ NMPA Key \\ Laboratory for Quality Control of \\ in vitro Diagnostics, National Medical \\ Products Administration, Beijing, People's \\ Republic of China; ${ }^{3}$ Beijing Engineering \\ Research Center of Immunological \\ Reagents Clinical Research, Beijing \\ Municipal Science and Technology \\ Commission, Beijing, People's Republic of \\ China
}

*These authors contributed equally to this work

\begin{abstract}
Aim: To evaluate the diagnostic and prognostic value of CSF presepsin levels in patients with postneurosurgical ventriculitis/meningitis (PNVM).

Methods: We conducted a case-control study to achieve our aims. First, we prospectively enrolled patients who had undergone neurosurgery in Beijing Tiantan Hospital from June to November 2020 and measured the CSF levels of 8 biomarkers, including presepsin and other meningitis biomarkers. The diagnostic and prognostic accuracies of presepsin levels were evaluated by determining the values for the area under the receiver operating characteristic curve (AUC).

Results: Two hundred thirty-nine patients were enrolled in this study; 34 were diagnosed with confirmed ventriculitis/meningitis (cVM), 138 were classified as probable ventriculitis/ meningitis $(\mathrm{pVM})$, and the others were rejected ventriculitis/meningitis (rVM). Presepsin levels effectively diagnose cVM and predict the outcomes of patients with PNVM, with thresholds of $1257.4 \mathrm{pg} / \mathrm{mL}$ and $1276.2 \mathrm{pg} / \mathrm{mL}$ and AUCs of 0.746 and 0.825 , respectively. Furthermore, a joint analysis with CSF lactate (C-Lac) levels shows that the AUCs of the two markers increased to 0.856 and 0.872 , respectively.

Conclusion: The rapid diagnosis and prediction of the clinical outcome is important in neurosurgery. CSF presepsin levels are an impressive diagnostic and prognostic biomarker for meningitis, and when combined with $\mathrm{C}$-Lac, they indeed improve the diagnostic and predictive efficiency of PNVM.
\end{abstract}

Keywords: presepsin, cerebrospinal fluid, postneurosurgical ventriculitis/meningitis

\section{Introduction}

Postneurosurgical ventriculitis/meningitis (PNVM) is one of the most serious and fatal infectious-related diseases worldwide and occurs after craniotomy, craniectomy, or following the insertion of internal or external ventricular and lumbar catheters. ${ }^{1}$ Patients with PNVM always experience serious complications associated with severe neurological sequelae, high mortality rates, a prolonged hospital stay, and high costs. ${ }^{2,3}$ The morbidity rate of PNVM varies in different papers, ranging from $1.5 \%$ to $25 \%,{ }^{4}$ but it can lead to a mortality rate of up to $35 \%$. Ideal PNVM treatment requires an accurate and early diagnosis and treatment.

PNVM has been divided into confirmed ventriculitis/meningitis (cVM) (with evidence of pathogens) and probable ventriculitis/meningitis (pVM) (without evidence of pathogens) in clinical practice. ${ }^{5}$ Since these patients present similar clinical symptoms, such as headache and fever, no distinction is made in most of
Correspondence: Chunqing Shao; Guojun Zhang

Tel +86 I8600I48997; +86 I58II2I94II

Email shaocq0210@।63.com;

zgjlunwen@163.com 
the clinical treatments. However, for patients with cVM, the use of antibiotics is crucial, and early antibiotic treatment can improve the prognosis and shorten the patient's hospital stay. ${ }^{6}$ Nevertheless, the inflammatory syndrome response of patients with $\mathrm{pVM}$, which is always caused by the detachment of tumor cells or the displacement of broken bones during the neurosurgical operation that does not require antibiotic treatment, and the excessive use of antibiotics may lead to dysbacteriosis in the patient. Therefore, discriminate the cVM and $\mathrm{pVM}$ is of great significance in clinical neurosurgical treatment, and in addition, antibiotic abuse may lead to the emergence of multidrug-resistant (MDR) bacteria and cause secondary central nervous system (CNS) infections.

The discrepancy between cVM and pVM is mainly due to the presence of pathogenic evidence, and pathogenic evidence is also the gold standard for the diagnosis of PNVM. However, a low positive rate of microbial culture, long-term culture, and a certain probability of contamination substantially affect the effective diagnosis of PNVM. ${ }^{7}$ Therefore, biomarkers are very important for the diagnosis of PNVM; however, conventional biomarkers such as the cerebrospinal fluid (CSF) leukocyte count (C-Leu), CSF protein concentration (C-Pro), and C-reactive protein (CRP) concentration possess low sensitivity and specificity, which block precise diagnosis and prognostic prediction in clinical treatment. ${ }^{8,9}$ Therefore, the development and evaluation of new biomarkers is very important in the diagnosis of PNVM.

As a new type of marker, sCD14 (presepsin) has received extensive clinical and laboratory attention. ${ }^{10,11} \mathrm{It}$ is a truncated subtype of soluble CD14 composed of 64 amino acids and induces the differentiation of activated macrophages in response to membrane-bound protein soluble fragment of 14 (CD14) expressed by bacterial lipopolysaccharides. ${ }^{12}$ CD14 is a coreceptor of Toll-like receptor 4 (TLR4) that binds the lipopolysaccharide (LPS)-lipopolysaccharide binding protein (LBP) complex, thereby promoting LPS-induced TLR4 activation. ${ }^{13}$ When metalloprotease is shed from the cell surface, the CD14LPS-LBP complex is released into body fluids, and the protease further cleaves this complex. Since it originated from bacterial pattern recognition, the level of free antiseptic protein in body fluids is considered a diagnostic biomarker of infection. Plasma presepsin levels are significantly increased in patients with sepsis, and its concentration is directly proportional to the severity of sepsis, ${ }^{14}$ with a high diagnostic sensitivity and specificity. At present, several studies have indicated that presepsin also exists in $\mathrm{CSF}^{15,16}$ and can be applied in the diagnosis of children with bacterial meningitis, but its ability to differentially diagnose clinical cVM and pVM has not been reported. Therefore, this study first established a baseline presepsin level in the CSF of patients who underwent neurosurgery and evaluated the discriminative value in the diagnosis of cVM and pVM. Afterwards, the prognostic ability of CSF presepsin levels was also evaluated.

\section{Study Design}

This prospective observational study was conducted in Beijing Tiantan Hospital from June-November 2020, and the study was approved by the ethics committee of Beijing Tiantan Hospital (NO: KY-2019-095-03), and this study was conducted in accordance with the Declaration of Helsinki, and participants or their relatives provided written informed consent. This study had three objectives. First, the baseline CSF presepsin concentration was measured in patients after neurosurgery. Second, the diagnostic ability of CSF presepsin levels in patients with PNVM was evaluated. Third, the prognostic ability of presepsin levels in patients with PNVM was explored.

Twelve clinical variables were extracted from the medical records of these patients in the database, including age (years), male sex (\%), site of surgery (head or spine), surgical wound classification (I or II), extraventricular drainage (EVD), lumbar drainage (LD), assisted mechanical ventilation (AMV), CSF leakage, craniotomy, Intensive care unit(ICU) admission, malignancy, and clinical outcomes. Eight clinical laboratory variables were extracted, including presepsin levels, C-Leu levels, CSF chloride ion concentration $(\mathrm{C}-\mathrm{Cl}), \mathrm{CSF}$ glucose concentration (C-Glu), CSF lactate (C-Lac) levels, CSF neutrophil ratio (C-Neu), C-Pro levels, and CRP levels. All clinical laboratory analyses were performed according to the manufacturer's instructions.

\section{Inclusion and Exclusion Criteria}

All patients who underwent neurosurgery were enrolled during the study period. Patients who were 18 years old and survived for at least 7 days after neurosurgery were eligible; neurosurgery included craniotomy, transsphenoidal surgery, spine surgery, etc. Because presepsin in the blood may affect the diagnostic experiment, patients with subarachnoid hemorrhage were excluded. Patients who had only intubation, drainage, and incomplete medical records were excluded. 
The study used the method reported in the literature to divide the patients into three groups. ${ }^{4,5} 1$ ) Rejected ventriculitis/meningitis (rVM): patients who underwent neurosurgery with a negative CNS culture and a CSF leukocyte count $<250$ cells/L with $<50 \%$ neutrophils. 2) cVM: patients who underwent neurosurgery with a positive CSF culture and a CSF leukocyte count $>250$ cells/L. 3) pVM: patients who underwent neurosurgery with a CSF leukocyte count $>1000$ cells/L with $>50 \%$ neutrophils or a count $>250$ cells $/ \mathrm{L}$ with $>50 \%$ neutrophils (if the patient had a history of steroid and/or antibiotic use at the time of the lumbar puncture). Patients with micrococcus, Corynebacterium and Propionibacterium infections were excluded.

\section{Statistical Analysis}

Continuous variables are presented as the means \pm SD or medians $(25 \%, 75 \%)$, which depends on whether the data conformed to a normal distribution. The Shapiro-Wilk method was employed to test for a normal distribution, and ANOVA, the Mann-Whitney $U$-test and Student's $t$ test were applied as the statistical methods to evaluate the significance of differences in the variables. Categorical data are presented as numbers and percentages, and the chi-square test or Fisher's exact test was performed as the statistical method. The diagnostic and prognostic ability of biomarkers of PNVM was evaluated using the MannWhitney $U$-test. $\mathrm{P}<0.05$ indicates that the difference is statistically significant. For the diagnostic and prognostic evaluations, the threshold, specificity, and sensitivity of CSF presepsin levels in the two groups were assessed by constructing receiver operating characteristic (ROC) curves. All statistical analyses were performed using
SPSS 20.0 software (IBM, New York, USA), and all figures were generated using Prism 7.0 software (GraphPad, San Diego, CA, USA).

\section{Results}

\section{Patients}

A total of 4665 neurosurgical patients were enrolled in this study, of whom 211 had meningitis syndrome. Of these patients, 18 had only CSF shunting, 7 were hospitalized for less than 7 days, 5 had anti-infective operations that were not performed in this hospital, and 9 had incomplete medical records. Of the remaining 172 patients, 34 were diagnosed with $\mathrm{cVM}$ and 138 were diagnosed with $\mathrm{pVM}$; meanwhile, 63 patients with rVM were randomly selected according to the exclusion criteria. The clinical characteristics of the patients are shown in Table 1. Body temperature, AMV, craniotomy, EVD, mortality, and reoperation showed statistically significant differences among the three groups.

Among the 34 patients cVM, 17 patients had grampositive bacterial cVM and 17 patients had gram-negative bacterial cVM. Staphylococcus epidermidis $(9,26.5 \%)$ and Klebsiella pneumoniae (7, 20.6\%) occupied the highest proportions, and the distributions of pathogens are shown in Table 2.

\section{Baseline Presepsin Levels in Neurosurgical Patients}

The median age of the 63 patients with rVM was 49 years, and the proportion of females was higher than that of males $(52.4 \%$ vs $47.6 \%)$. The average CSF presepsin concentration was $348.3 \pm 97.2 \mathrm{pg} / \mathrm{mL}$.

Table I Clinical Characteristics of cVM, pVM and rVM Patients

\begin{tabular}{|l|l|l|l|l|}
\hline Parameter & cVM(34) & PVM(138) & rVM(63) & P \\
\hline Age & $48(31,63)$ & $47(32,55)$ & $49.0(34.0,59.0)$ & 0.633 \\
Gender (male) & $20(58.8 \%)$ & $74(53.6 \%)$ & $33(52.4 \%)$ & $36.5(36.4,36.6)$ \\
Body temperature $\left({ }^{\circ} \mathrm{C}\right)$ & $37.0(36.5,38.2)$ & $36.8(36.4,37.8)$ & $10(15.9 \%)$ & 0.822 \\
AMV & $6(17.6 \%)$ & $8(5.8 \%)$ & $35(55.6 \%)$ & $<0.001$ \\
Craniotomy & $26(76.5 \%)$ & $108(80.6 \%)$ & $6(9.5 \%)$ & $11(17.5 \%)$ \\
CSF leakage & $7(20.6 \%)$ & $13(9.4 \%)$ & $25(39.7 \%)$ & 0.028 \\
EVD & $14(41.2 \%)$ & $26(18.8 \%)$ & $15(23.8 \%)$ & 0.122 \\
ICU admission & $21(61.8 \%)$ & $58(42.0 \%)$ & $25(39.7 \%)$ & 0.012 \\
LD & $11(32.4 \%)$ & $39(28.3 \%)$ & $0(0 \%)$ & 0.081 \\
Malignant tumor & $18(52.9 \%)$ & $56(40.6 \%)$ & $6(9.5 \%)$ & 0.649 \\
Mortality & $10(29.4 \%)$ & $5(3.6 \%)$ & $49(77.7 \%)$ & $<0.001$ \\
Reoperation & $17(50 \%)$ & $16(11.6 \%)$ & $<0.001$ \\
Type of the surgery & $23(67.6 \%)$ & $102(73.9 \%)$ & 0.554 \\
\hline
\end{tabular}


Table 2 Distribution of Pathogens of cVM

\begin{tabular}{|c|c|c|c|}
\hline Group & Isolates & Numbers (34) & Percentage (100\%) \\
\hline \multirow[t]{5}{*}{ Gram positive bacterial cVM } & Enterococcus faecalis & 2 & $5.9 \%$ \\
\hline & Enterococcus faecium & I & $2.9 \%$ \\
\hline & Staphylococcus aureus & 4 & $11.8 \%$ \\
\hline & Staphylococcus epidermidis & 9 & $26.5 \%$ \\
\hline & Staphylococcus hominis & I & $2.9 \%$ \\
\hline \multirow[t]{6}{*}{ Gram Negative bacterial cVM } & Acinetobacter baumannii & 3 & $8.8 \%$ \\
\hline & Acinetobacter jungii & I & $2.9 \%$ \\
\hline & Chryseobacterium indolegenes & $\mathrm{I}$ & $2.9 \%$ \\
\hline & Klebsiella pneumoniae & 7 & $20.6 \%$ \\
\hline & Proteus mirabilis & I & $2.9 \%$ \\
\hline & Stenotrophomonas maltophilia & 4 & $11.8 \%$ \\
\hline
\end{tabular}

\section{Diagnostic Ability of Presepsin and C-Lac Levels}

Table 3 shows the blood- and CSF-related biomarkers in patients with cVM and pVM. Significant differences in multiple biomarkers, such as presepsin, C-Leu, C-Lac, C-Pro, Leu, LY\%, and Neu\%, were observed between patients with $\mathrm{cVM}$ and patients with pVM. The CSF presepsin concentration in patients with cVM was significantly higher than that of patients with pVM $(1462.2 \pm 353.9 \mathrm{pg} / \mathrm{mL}$ vs $1203.8 \pm 380.8$ $\mathrm{pg} / \mathrm{mL} \mathrm{P}<0.001)$. The ROC curve analysis showed that for the differential diagnosis of $\mathrm{cVM}$ and $\mathrm{pVM}$, the best threshold value was $1257.5 \mathrm{pg} / \mathrm{mL}$, and the area under the curve (AUC) of presepsin levels was 0.725 , with a sensitivity and NPV of $88.2 \%$ and $83.9 \%$, respectively. As shown in Table 3 , $\mathrm{C}$-Lac levels also had a good diagnostic ability $(\mathrm{AUC}=0.808)$. The diagnosis based on the combination of presepsin and C-Lac levels showed an effective improvement of the discriminate diagnostic efficiency of $\mathrm{cVM}$ and $\mathrm{pVM}(\mathrm{AUC}=0.856)$, and the sensitivity and specificity were $82.8 \%$ and $73.5 \%$, respectively. Other ROC parameters are shown in Table 4 and Figure 1.
In addition, 34 patients with cVM were grouped into infections with gram-negative and gram-positive bacteria. The presepsin concentration in the gram-positive bacteria group was higher than that in the gram-negative bacteria group (1526.5 $\pm 405.6 \mathrm{pg} / \mathrm{mL}$ vs $1464.2 \pm 312.1 \mathrm{pg} / \mathrm{mL})$; however, the difference between the two groups was not significant $(\mathrm{P}=0.358)$.

\section{Prognostic Ability of Presepsin and C-Lac Levels}

In this study, 15 patients had a poor prognosis (nonsurvived group) due to PNVM, and the other 157 patients were successfully cured (survived). Among them, clinical biomarkers, including presepsin, are shown in Table 5. The concentration of presepsin in the surviving group was $1224.2 \pm 381.2 \mathrm{pg} / \mathrm{mL}$, and the presepsin concentration in the nonsurviving group was $1642.8 \pm 286.2 \mathrm{pg} / \mathrm{mL}$. The univariate analysis showed that presepsin and C-Lac levels were significantly different in the two groups (Table 5).

The multivariate regression analysis showed that presepsin and C-Lac levels are potentially useful as

Table 3 Clinical Laboratory Parameters of cVM, pVM and rVM Patients

\begin{tabular}{|c|c|c|c|}
\hline Parameter & cVM(34) & $\operatorname{pVM}(138)$ & $\mathbf{P}$ \\
\hline C-Leu $\left(10^{6} / \mathrm{L}\right)$ & $2489.0(9|2.3,1| 43.5)$ & $2291.0(740.0,4 \mid 83.8)$ & 0.117 \\
\hline $\mathrm{C}-\mathrm{Cl}(\mathrm{mmol} / \mathrm{L})$ & $119.3 \pm 10.4$ & $120.2 \pm 6.5$ & 0.978 \\
\hline C-Glu (mmol/L) & $1.8 \pm 2.0$ & $2.8 \pm 1.2$ & 0.005 \\
\hline C-Lac(mg/dl) & $10.1 \pm 4.4$ & $6.0 \pm 1.8$ & $<0.001$ \\
\hline C-Neu(\%) & $81.6 \pm 20.6$ & $81.1 \pm 16.2$ & 0.144 \\
\hline C-Pro $(g / L)$ & $255.4(160.9,422.6)$ & I59.8(II7.3, 209.5) & 0.001 \\
\hline $\mathrm{CRP}(\mathrm{mg} / \mathrm{L})$ & $66.2(24.3,115.5)$ & $26.4(10.2,50.1)$ & 0.020 \\
\hline Presepsin $(\mathrm{pg} / \mathrm{mL})$ & $1462.2 \pm 353.9$ & $1203.8 \pm 380.8$ & $<0.001$ \\
\hline
\end{tabular}


Table 4 ROC Parameters of the Discrimination of cVM and pVM Patients

\begin{tabular}{|c|c|c|c|c|c|c|c|c|c|}
\hline Parameters & AUC & Threshold & SEN & SEP & PPV & NPV & PLR & NLR & $\begin{array}{c}\text { Younden } \\
\text { Index }\end{array}$ \\
\hline C-Lac & 0.808 & $7.8 \mathrm{mg} / \mathrm{dl}$ & $61.8 \%$ & $91.2 \%$ & $87.5 \%$ & $70.5 \%$ & 7.023 & 0.419 & 0.519 \\
\hline Presepsin & 0.746 & $1257.4 \mathrm{pg} / \mathrm{mL}$ & $88.2 \%$ & $61.6 \%$ & $69.7 \%$ & $83.9 \%$ & 2.297 & 0.192 & 0.498 \\
\hline C-Pro & 0.693 & $248.6 \mathrm{~g} / \mathrm{L}$ & $55.9 \%$ & $84.4 \%$ & $78.2 \%$ & $65.7 \%$ & 3.583 & 0.523 & 0.403 \\
\hline CRP & 0.679 & $39.7 \mathrm{mg} / \mathrm{L}$ & $68.4 \%$ & $70.2 \%$ & $69.7 \%$ & $69.0 \%$ & 2.295 & 0.450 & 0.386 \\
\hline C-Glu & 0.657 & $0.9 \mathrm{mmol} / \mathrm{L}$ & $94.3 \%$ & $52.9 \%$ & $66.7 \%$ & $90.3 \%$ & 2.002 & 0.108 & 0.472 \\
\hline $\begin{array}{l}\text { Fitted } \\
\text { variable }\end{array}$ & 0.856 & 0.786 & $82.8 \%$ & $73.5 \%$ & $75.8 \%$ & $81.0 \%$ & 3.125 & 0.234 & 0.563 \\
\hline
\end{tabular}

Abbreviations: SEN, sensitivity; SEP, specificity; PPV, positive predictive value; NPV, negative predictive value; PLR, positive likelihood ratio; NLR, negative likelihood ratio.

independent predictors of a poor prognosis (Table 5), with the best threshold values being $1276.2 \mathrm{pg} / \mathrm{mL}$ and 12.2 $\mathrm{mmol} / \mathrm{l}$, respectively. The diagnosis based on the combination of presepsin and C-Lac levels indeed showed an improved diagnostic efficiency, with an $\mathrm{AUC}=0.872$ and a sensitivity as high as $100.0 \%$, suggesting that these parameters predict the clinical outcome of meningitis. Other ROC curve parameters are shown in Table 6 and Figure 2.

\section{Discussion}

PNVM is a complication of neurosurgery that has become a social problem and has a very important clinical status. The diagnosis of PNVM in patients who underwent neurosurgery is frequently presumptive because of the low diagnostic sensitivity and specificity of conventional biomarkers. ${ }^{17}$ Different types of PNVM require different treatment procedures, and an accurate diagnosis has strong clinical significance. In addition to the diagnosis of clinical symptoms, novel, reliable biomarkers with high sensitivity and specificity are urgently needed to assist with the diagnosis and predict the prognosis of PNVM.

In this prospective study, we concluded that presepsin is a biomarker with diagnostic and prognostic abilities for PNVM. The CSF concentration of presepsin in patients with PNVM increased significantly compared with that in patients with rVM, and the average CSF presepsin level of 63 patients with rVM was $328.3 \pm 97.2 \mathrm{pg} / \mathrm{mL}$. In contrast, presepsin levels were significantly elevated in the CSF of patients with $\mathrm{cVM}$ and $\mathrm{pVM}$, and the difference between the two groups was statistically significant $(\mathrm{P}<0.05)$. The joint diagnosis based on C-Lac and presepsin levels showed that the discriminate diagnostic efficiency of $\mathrm{cVM}$ and $\mathrm{pVM}$ was effectively improved (AUC $=0.856$ ). The prognostic analysis showed a significantly higher presepsin level in patients with a poor prognosis than in patients with a good prognosis $(1642.8 \pm 286.2 \mathrm{pg} / \mathrm{mL}$ vs $1224.2 \pm 381.2 \mathrm{pg} / \mathrm{mL}$ ), and the best threshold value was $1276.2 \mathrm{pg} / \mathrm{mL}$. A joint analysis of presepsin and C-Lac levels achieved a better prognostic evaluation
A

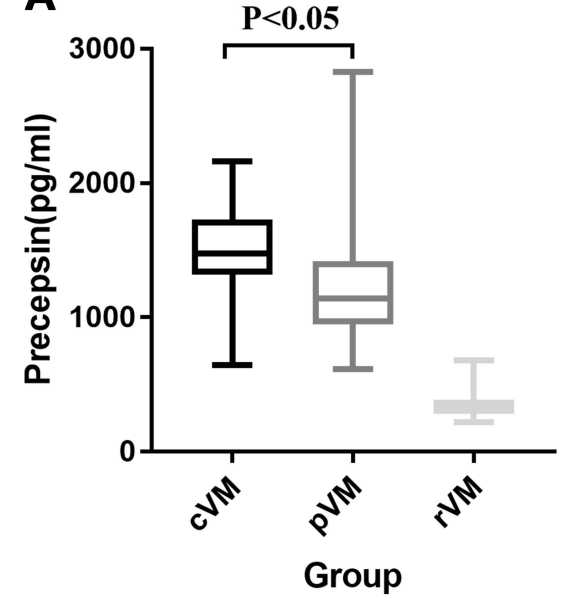

B

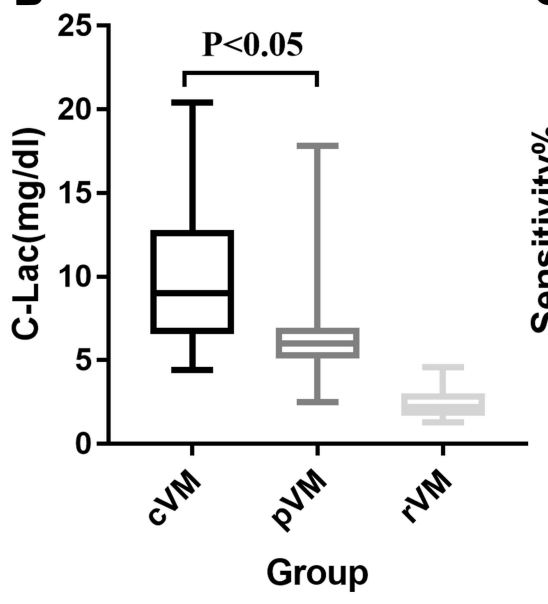

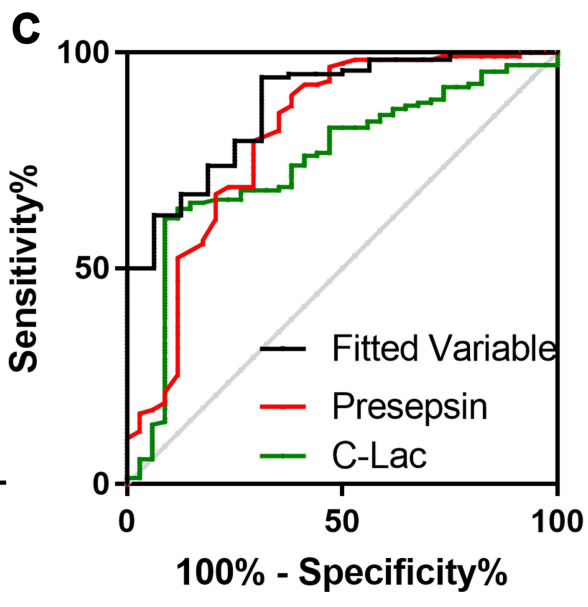

Figure I Concentration of CSF presepsin (A) and C-Lac (B) in cVM, pVM and rVM patients; ROC of presepsin, C-Lac and joint analysis of them in diagnosis of cVM (C). 
Table 5 Clinical Laboratory Parameters of Non-Survived and Survived Patients

\begin{tabular}{|c|c|c|c|c|c|c|}
\hline Parameters & Non-Survived(15) & Survived(157) & $\mathbf{P}$ & OR & 95\%C.I. & $\mathbf{P}$ \\
\hline Presepsin(pg/mL) & $1642.8 \pm 286.2$ & $1224.2 \pm 38 \mid .2$ & $<0.001$ & 1.002 & $1.001-1.003$ & 0.003 \\
\hline C-Leu( $\left(10^{6} / \mathrm{L}\right)$ & $\begin{array}{l}3562.0(1328.5, \\
8207.0)\end{array}$ & $22 \mid 4.0(782.0,4592.0)$ & 0.126 & & & \\
\hline C-Neu(\%) & $78.0 \pm 23.4$ & $81.7 \pm 16.5$ & 0.721 & & & \\
\hline C-Pro $(g / L)$ & $253.9(141.6,430.8)$ & $163.4(117.7,227.0)$ & 0.074 & & & \\
\hline $\mathrm{C}-\mathrm{Cl}^{-}(\mathrm{mmol} / \mathrm{L})$ & $122.2 \pm 11.9$ & $117.9 \pm 6.9$ & 0.272 & & & \\
\hline C-Glu(mmol/L) & $\mathrm{I} .7 \pm \mathrm{I} .4$ & $2.3 \pm 1.4$ & 0.166 & & & \\
\hline C-Lac(mg/dl) & $10.6 \pm 4.7$ & $6.6 \pm 2.5$ & $<0.001$ & 1.297 & I.126-1.495 & $<0.001$ \\
\hline $\mathrm{CRP}(\mathrm{mg} / \mathrm{L})$ & $79.8(44.1,109.8)$ & $26.7(10.7,66.2)$ & 0.080 & & & \\
\hline
\end{tabular}

Abbreviations: OR, odds ratio; 95\%C.I, 95\% confidence interval.

Table 6 ROC Parameters of the Prognostic Ability of Presepsin and C-Lac

\begin{tabular}{|l|l|c|c|c|c|c|c|c|c|}
\hline Parameter & AUC & Threshold & SEN & SEP & PPV & NPV & PLR & NLR & Youden Index \\
\hline Presepsin & 0.825 & $1276.2 \mathrm{pg} / \mathrm{mL}$ & $93.3 \%$ & $58.7 \%$ & $69.3 \%$ & $89.8 \%$ & 2.259 & 0.114 & 0.520 \\
C-Lac & 0.782 & $12.2 \mathrm{mg} / \mathrm{dl}$ & $46.7 \%$ & $96.5 \%$ & $93.0 \%$ & $64.4 \%$ & 13.343 & 0.552 & 0.431 \\
Fitted Variable & 0.872 & 0.0542 & $100.0 \%$ & $67.4 \%$ & $75.4 \%$ & $100.0 \%$ & 3.067 & 0.000 & 0.674 \\
\hline
\end{tabular}

Abbreviations: SEN, sensitivity; SEP, specificity; PPV, positive predictive value; NPV, negative predictive value; PLR, positive likelihood ratio; NLR, negative likelihood ratio.

$(\mathrm{AUC}=0.872)$. To the best of our knowledge, this study is the first to perform a differential diagnostic and prognostic evaluation of presepsin levels in the CSF of patients with PNVM.

Because presepsin is produced by macrophages in the systemic circulation, it may be secreted by central neuroglia to address pathogen infection and other noxious stimuli. Different articles have reported similar but not the same CSF presepsin concentrations in people.
Abudeev reported that the range of presepsin levels in people without neurosurgery was $50-100 \mathrm{pg} / \mathrm{mL},{ }^{15}$ while the study by Carpio reported a concentration of $153 \mathrm{pg} / \mathrm{mL}^{18}$ In our study, the presepsin level in patients without an infection after neurosurgery (rVM) was higher than that in people without neurosurgery. ${ }^{15}$ The potential explanation is that the patient has an inflammatory response after surgical trauma. Compared with patients without surgery, macrophages secrete

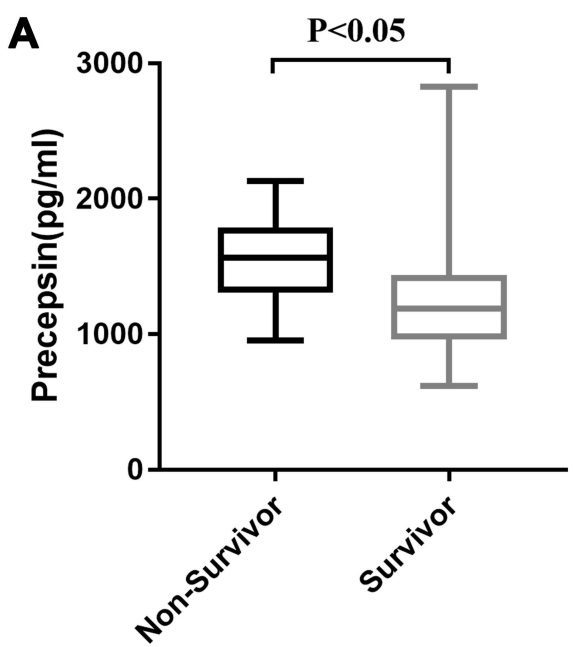

Group

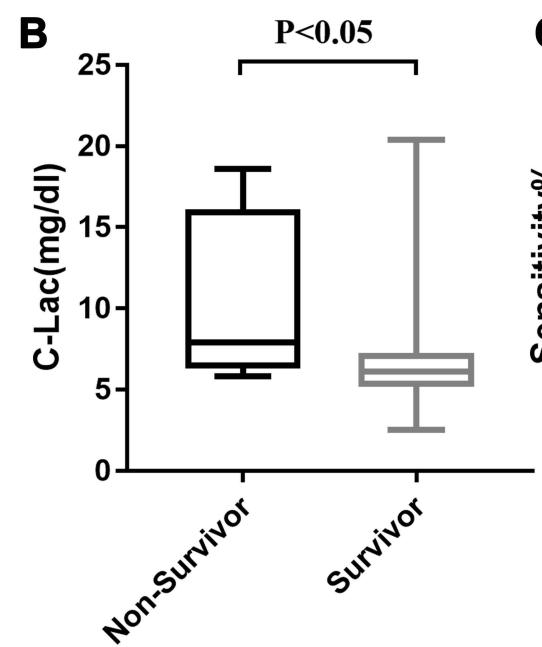

Group

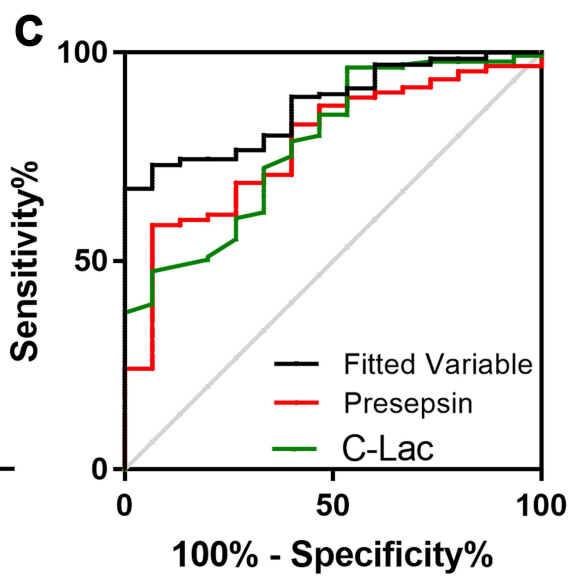

Figure 2 Concentration of CSF presepsin (A) and C-Lac (B) in non-survivor and survivor patients; ROC of presepsin, C-Lac and joint analysis of them in prognostic of $\operatorname{PNVM}(\mathbf{C})$. 
presepsin, resulting in an increase in the CSF concentration.

Presepsin is mainly used as a clinical diagnostic marker for various diseases, such as infection, kidney function, ${ }^{19}$ perioperative medicine, ${ }^{20,21}$ and cardiac arrest. The most famous and significant usage in the clinic is the diagnosis of sepsis, as it shows a higher diagnostic value than other biomarkers. The severity of sepsis is strongly associated with presepsin concentrations and the day of measurement, whereas PCT and CRP levels are not significantly different. $^{22}$

Because serum presepsin levels can predict the severity of sepsis, we speculate that presepsin can distinguish $\mathrm{cVM}$ from $\mathrm{pVM}$. The analysis of CSF presepsin levels in patients with cVM and $\mathrm{pVM}$ showed that the discrimination of the two groups was more certain if presepsin was employed. A ROC curve analysis of clinical laboratory data indicates that CSF presepsin levels have an AUC of 0.746 and a threshold value of $1257.4 \mathrm{pg} / \mathrm{mL}$, which are better than the majority of traditional infectious biomarkers. Thus, when the patient's CSF presepsin level is higher than $1257.4 \mathrm{pg} / \mathrm{mL}$, the patient tends to have cVM. Under normal circumstances, the severity of $\mathrm{cVM}$ is higher than that of $\mathrm{pVM}$. Other papers indicate that presepsin levels in patients with sepsis are related to the disease severity. ${ }^{23-25}$ Therefore, in the diagnosis of nervous system infections, the role of CSF presepsin levels is similar to its levels in plasma. Compared with C-Lac levels, the diagnostic value of presepsin levels was slightly lower ( 0.746 vs 0.808$)$, but the diagnostic sensitivity of presepsin was much higher $(88.2 \%$ vs $61.8 \%)$. It can be used in a preliminary screen for the discrimination of $\mathrm{cVM}$ and $\mathrm{pVM}$. In the joint diagnosis based on multiple indicators, ${ }^{26}$ the diagnostic ability of a single marker is significantly improved. Through the joint diagnostic analysis of the two biomarkers, both the low sensitivity and specificity of C-Lac and presepsin levels can be eliminated.

Several studies have shown that some biomarkers distinguish gram-positive and gram-negative bacterial infections, for example, C-Lac levels distinguish the two groups. ${ }^{27,28}$ Nevertheless, the conclusion of the present study shows that presepsin does not distinguish gram-positive from gramnegative cVM $(\mathrm{p}>0.05)$. The potential explanation is that gram-positive bacteria or gram-negative bacteria stimulate macrophages to produce presepsin, and the magnitude of the response is only related to the severity of the infection in the patient, rather than the type of microorganism.
For the predictive study of the clinical outcomes of PNVM, neurosurgical patients are usually evaluated by measuring independent risk factors. According to published reports, the survival analysis of hospitalized patients with sepsis shows that presepsin can be used as an independent risk factor for death. ${ }^{29}$ In contrast, few studies target the screening of predictors of PNVM, and only clinical indicators such as the GCS score predict the clinical outcomes of infected patients. ${ }^{3}$ Based on the results of the present study, presepsin is potentially useful as an independent predictor of the clinical outcomes of patients, with an $\mathrm{AUC}=0.825$ and sensitivity and specificity of $93.3 \%$ and $58.7 \%$, respectively. When combined with C-Lac levels, mortality is better predicted $(\mathrm{AUC}=0.872$ ), and the sensitivity is as high as $100 \%$.

Our study has a number of limitations. First, this study was conducted at a single center, and the generality of the results is slightly insufficient. Second, only 172 patients with $\mathrm{cVM}$ and $\mathrm{pVM}$ and 63 patients with $\mathrm{rVM}$ were enrolled in this study, which are relatively low numbers. Third, we did not evaluate presepsin levels in blood samples from patients with PNVM. Fourth, the validation experiment of the target biomarkers were not carried out, which may slightly reduce the accuracy of the experiment. In future studies, 3-5 neurosurgical centers in northern China will be included, and the validation test will be conducted to better evaluate the diagnostic and prognostic value of presepsin levels.

In summary, the average CSF presepsin concentration in patients after neurosurgery was $348.3 \pm 97.2 \mathrm{pg} / \mathrm{mL}$. CSF presepsin has the ability to differentially diagnose and predict PNVM, and when presepsin is used in combination with C-Lac, it substantially improves the diagnostic efficiency. Overall, CSF presepsin is a promising diagnostic and prognostic biomarker for meningitis and further clinical evaluations are needed.

\section{Acknowledgment}

We would like to thank Yijun Shi for helping the authors in collecting the data.

\section{Funding}

The study was funded by Beijing Municipal Administration of Hospitals (NO: QML20180502).

\section{Disclosure}

The authors report no conflicts of interest in this work. 


\section{References}

1. Bari ME, Haider G, Malik K, Waqas M, Mahmood SF, Siddiqui M. Outcomes of post-neurosurgical ventriculostomy-associated infections. Surg Neurol Int. 2017;8:124. doi:10.4103/sni.sni_440_16

2. Zheng G, Li S, Zhao M, et al. Time to positive culture can differentiate post-neurosurgical coagulase-negative Staphylococci other than $\mathrm{S}$ epidermidis meningitis from contamination: a case-control observational study. $J$ Clin Lab Anal. 2020;34(10):e23447. doi: $10.1002 /$ jcla. 23447

3. Shi YJ, Zheng GH, Qian LY, Qsman RA, Li GG, Zhang GJ. Longitudinal analysis of risk factors for clinical outcomes of enterobacteriaceae meningitis/encephalitis in post-neurosurgical patients: a comparative cohort study during 2014-2019. Infect Drug Resist. 2020;13:2161-2170. doi:10.2147/IDR.S252331

4. Hernández Ortiz OH, García García HI, Muñoz Ramírez F, et al. Development of a prediction rule for diagnosing postoperative meningitis: a cross-sectional study. $J$ Neurosurg. 2018;128 (1):262-271. doi:10.3171/2016.10.JNS16379

5. Leib SL, Boscacci R, Gratzl O, Zimmerli W. Predictive value of cerebrospinal fluid (CSF) lactate level versus CSF/blood glucose ratio for the diagnosis of bacterial meningitis following neurosurgery. Clin Infect Dis. 1999;29(1):69-74. doi:10.1086/520184

6. Wang Y, Lei X, Zhao Y, et al. An improved clinical prediction rule for identifying neonatal bacterial meningitis: a multicenter cohort study. Transl Pediatr. 2021;10(1):64-72. doi:10.21037/tp-20-255

7. Sipahi OR, Mermer S, Demirdal T, et al. Tigecycline in the treatment of multidrug-resistant Acinetobacter baumannii meningitis: results of the Ege study. Clin Neurol Neurosurg. 2018;172:31-38. doi:10.1016/ j.clineuro.2018.06.008

8. Alnomasy SF, Alotaibi BS, Mujamammi AH, Hassan EA, Ali ME. Microbial aspects and potential markers for differentiation between bacterial and viral meningitis among adult patients. PLoS One. 2021;16(6):e0251518. doi:10.1371/journal.pone.0251518

9. Mirkhani A, Roshanpoor A, Pournik O, Haddadi H, Mirzaei J, Kaveh F. Developing a prognostic model to predict mortality in patients with acute bacterial meningitis. Stud Health Technol Inform. 2021;281:774-778.

10. Azim A. Presepsin: a promising biomarker for sepsis. Indian J Crit Care Med. 2021;25(2):117-118.

11. Aulin L, de Lange DW, Saleh M, van der Graaf PH, Völler S, van Hasselt J. Biomarker-guided individualization of antibiotic therapy. Clin Pharmacol Ther. 2021. doi:10.1002/cpt.2194

12. Yaegashi Y, Shirakawa K, Sato N, et al. Evaluation of a newly identified soluble CD14 subtype as a marker for sepsis. J Infect Chemother. 2005;11(5):234-238. doi:10.1007/s10156-005-0400-4

13. Mussap M, Noto A, Fravega M, Fanos V. Soluble CD14 subtype presepsin (sCD14-ST) and lipopolysaccharide binding protein (LBP) in neonatal sepsis: new clinical and analytical perspectives for two old biomarkers. J Matern Fetal Neonatal Med. 2011;24(Suppl 2):12-14. doi:10.3109/14767058.2011.601923

14. Drăgoescu AN, Pădureanu V, Stănculescu AD, et al. Presepsin as a potential prognostic marker for sepsis according to actual practice guidelines. J Pers Med. 2020;11(1). doi:10.3390/jpm11010002

15. Abudeev SA, Kiselev KV, Kruglyakov NM, et al. Cerebrospinal fluid presepsin as a marker of nosocomial infections of the central nervous system: a Prospective Observational Study. Front Neurol. 2018;9:58. doi:10.3389/fneur.2018.00058
16. Stubljar D, Kopitar AN, Groselj-Grenc M, Suhadolc K, Fabjan T, Skvarc M. Diagnostic accuracy of presepsin (sCD14-ST) for prediction of bacterial infection in cerebrospinal fluid samples from children with suspected bacterial meningitis or ventriculitis. $J$ Clin Microbiol. 2015;53(4):1239-1244. doi:10.1128/JCM.03052-14

17. Zhang G, Yang C, Kang X, Gao Z, Wan H, Liu Y. The combination of cerebrospinal fluid procalcitonin, lactate, interleukin-8 and interleukin-10 concentrations for the diagnosis of postneurosurgical bacterial meningitis: a prospective study. Ann Clin Biochem. 2019;56 (1):133-140. doi:10.1177/0004563218794729

18. Carpio R, Zapata J, Spanuth E, Hess G. Utility of presepsin (sCD14-ST) as a diagnostic and prognostic marker of sepsis in the emergency department. Clin Chim Acta. 2015;450:169-175. doi:10.1016/j.cca.2015.08.013

19. Kobayashi S, Amano H, Terawaki H, Kawaguchi Y, Yokoo T. Prediction of presepsin concentrations through commensurate decline in kidney function in the elderly. Clin Chim Acta. 2020;500:1-9. doi:10.1016/j.cca.2019.09.012

20. Handke J, Piazza O, Larmann J, Tesoro S, De Robertis E. Presepsin as a biomarker in perioperative medicine. Minerva Anestesiol. 2020;86(7):768-776. doi:10.23736/S0375-9393.20.14169-5

21. Qi Z, Zhang Q, Liu B, Shao F, Li C. Presepsin as a biomarker for evaluating prognosis and early innate immune response of out-ofhospital cardiac arrest patients after return of spontaneous circulation. Crit Care Med. 2019;47(7):e538-e546. doi:10.1097/CCM.00000 00000003764

22. Aliu-Bejta A, Atelj A, Kurshumliu M, Dreshaj S, Baršić B. Presepsin values as markers of severity of sepsis. Int J Infect Dis. 2020;95:1-7. doi:10.1016/j.ijid.2020.03.057

23. Ferrarese A, Frigo AC, Mion MM, et al. Diagnostic and prognostic role of presepsin in patients with cirrhosis and bacterial infection. Clin Chem Lab Med. 2020;59:775.

24. Tambo M, Taguchi S, Nakamura Y, Okegawa T, Fukuhara H. Presepsin and procalcitonin as predictors of sepsis based on the new Sepsis-3 definitions in obstructive acute pyelonephritis. $B M C$ Urol. 2020;20(1):23. doi:10.1186/s12894-020-00596-4

25. Yoon SH, Kim EH, Kim HY, Ahn JG. Presepsin as a diagnostic marker of sepsis in children and adolescents: a systemic review and meta-analysis. BMC Infect Dis. 2019;19(1):760. doi:10.1186/s12879019-4397-1

26. Zheng G, Ji X, Yu X, et al. Development and verification of a discriminate algorithm for diagnosing post-neurosurgical bacterial meningitis-A multicenter observational study. J Clin Lab Anal. 2020;34(2):e23069. doi:10.1002/jcla.23069

27. Yan ST, Sun LC, Jia HB, Gao W, Yang JP, Zhang GQ. Procalcitonin levels in bloodstream infections caused by different sources and species of bacteria. Am J Emerg Med. 2017;35(4):579-583. doi:10.1016/j.ajem.2016.12.017

28. Leli C, Ferranti M, Moretti A, Al Dhahab ZS, Cenci E, Mencacci A. Procalcitonin levels in gram-positive, gram-negative, and fungal bloodstream infections. Dis Markers. 2015;2015:701480. doi: $10.1155 / 2015 / 701480$

29. Wen MY, Huang LQ, Yang F, et al. Presepsin level in predicting patients' in-hospital mortality from sepsis under sepsis-3 criteria. Ther Clin Risk Manag. 2019;15:733-739. doi:10.2147/TCRM. S209710 


\section{Publish your work in this journal}

Infection and Drug Resistance is an international, peer-reviewed openaccess journal that focuses on the optimal treatment of infection (bacterial, fungal and viral) and the development and institution of preventive strategies to minimize the development and spread of resistance. The journal is specifically concerned with the epidemiology of antibiotic resistance and the mechanisms of resistance development and diffusion in both hospitals and the community. The manuscript management system is completely online and includes a very quick and fair peerreview system, which is all easy to use. Visit http://www.dovepress.com/ testimonials.php to read real quotes from published authors.

Submit your manuscript here: https://www.dovepress.com/infection-and-drug-resistance-journal 